\title{
Complex interactions of water, air and its controlled removal during pipeline filling operations
}

\begin{abstract}
Removing air from pipelines during filling operations is a complex fluid design and modelling challenge. In order to explore the influence of air valves on the transient response of a pipe system during rapid filling, the conventional air valve boundary condition is extended to account for the main features of the two-phase flow established in the downstream piping. A shock-fitting numerical model simultaneously tracks the filling water column, the response of the air valve and the possibility of column separation. The extended air valve boundary condition is shown both to permit a more realistic representation of the filling hydraulics and to fix a flaw with the conventional air valve boundary condition that sometimes causes it to converge to an incorrect steady state condition. It is also confirmed that the presence of an air-vacuum valve, while effectively preventing negative pressure and local liquid vaporization, can still permit column separation and that the rapid expulsion of the admitted air can induce severe secondary transient pressures. However, the secondary transient pressures captured by the conventional air valve boundary conditions are shown to be overly sensitive to the shape of pipeline profile. Finally it is demonstrated that the proposed air valve boundary condition nicely represents air binding at the high point and the associated overall reduction in the conveyance capacity of a pipe system.
\end{abstract}

Volume 3 Issue I - 2019

\author{
A Malekpour,' BW Karney² \\ Hydraulic Specialist, Hydra Tek \& Associates, Canada \\ ${ }^{2}$ Professor, University of Toronto, Canada
}

Correspondence: A Malekpour, Hydraulic Specialist, Hydra Tek \& Associates, 216 Chrislea Road, Suite 204,Vaughan, On, L4L 8S5, Canada, Email a.malekpour@hydratek.com

Received: January 29, 2019 | Published: February 21, 2019

Keywords: rapid filling, air valves, column separation, transient analysis, water hammer, method of characteristics

\section{Introduction}

Free air may intrude into pipe systems in many ways. These ways include the formation of vortexes at pipe entrances or pump sumps, the release of dissolved air due to pressure drop at high points and/or the increase of turbulent intensity at flow restrictions, the leakage of air through deteriorated packing at joints and valves in the presence of vacuum pressure or even due to incomplete filling operations. ${ }^{1,2}$ Incomplete removal of air from pipe systems may increase head losses and thus decrease the system's conveyance capacity, and it may also induce intermitted flows caused by explosive release of entrapped air pockets. ${ }^{3}$ Air creates many fluid mechanical complications that set the larger stage for more detailed consideration of specific air-water effects.

Air valves are therefore routinely employed to practically manage air in pipe systems. Although there are many air valves on the market, they are often categorized as of two basic types: air release valves (ARVs) and air vacuum valves (AVVs). ARVs, sometimes known as 'automatic air valves' or 'small-orifice air valves', are employed to continually release free air from pipes during normal operation. AVVs are conventionally expected to both release large content of air during the initial filling of pipe systems and to admit air while the system is being drained. The operational failure of AVVs may have quite destructive consequences, sometimes exposing the pipe system to detrimental negative and positive pressures.

In addition to conventional usage, $\mathrm{AVV}$ s are also employed as an efficient tool to alleviate negative pressures during transient flows. In such cases, the negative pressures are locally circumvented through admitting air at the high points of pipe profiles where the pressures are most likely to drop below atmospheric. Lingireddy et al., ${ }^{4}$ Lee, ${ }^{5}$ Lee et al., ${ }^{6}$ Chaiko et al. ${ }^{7}$ and Carlos et al. ${ }^{8}$ among others have shown that
AVVs may efficiently prevent transient negative pressures. However, these researchers also reported that secondary transient pressures are likely to occur if the air is explosively released through the air valves, observing that smaller outflow nozzles may significantly moderate the secondary transient pressures. Such AVVs are often called 'anti slam' or 'anti surge' valves.'

Yet there are some other operational conditions which may cause AVVs to be activated and to produce adverse transient pressures. Many attempts have been made to explore the adverse consequence of rapid filling in pipe systems ${ }^{10}$ Malekpour et al. ${ }^{11}$ Zhou et al., ${ }^{12}$ Martin, ${ }^{13}$ Cabrera, ${ }^{14}$ Liu et al., ${ }^{15}$ Carlos et al.,${ }^{8}$ Bergant et al., ${ }^{16}$ though to date, there has been little exploration of how air valves can affect the hydraulics of filling. Certainly, rapid filling may induce negative pressure, column separation and cavity collapse, resulting in harmful water hammer pressures. Column separation is a well-known phenomenon in pressurized pipe systems and has been received considerable attention Simpson et al., ${ }^{17}$ Bergant, Simpson, ${ }^{18}$ Chaiko, ${ }^{19}$ Adamkowski et al. ${ }^{20}$ List et al., ${ }^{21}$ Liou, Hunt, ${ }^{22}$ proposed a rigid column model for rapid filling in an undulating pipeline and showed that negative pressure and column separation may occur at high points. However, their model did not account for water column separation. Malekpour et al., ${ }^{23-25}$ numerically explored column separation during rapid pipe filling, identifying three conditions under which column separation could induce strong overpressures. These studies, however, did not consider the effects of air valves on the filling hydraulics. In real pipe systems, air valves are usually found at high points and these are often activated during rapid filling. In such cases air admitted to the system can alleviate the negative pressure and limit liquid vaporization. The goal of the current paper is to investigate the interaction between rapid filling, column separation and air valve performance. To this end, a shock capturing model is employed to track the filling water column and to capture induced water hammer pressures. The conventional 
approach in air valve modeling is extended to capture some important features of the two-phase flows established in downstream piping. The numerical model allows several key questions to be addressed: (1) To what extent can AVVs protect pipelines against negative pressures and column separation during rapid filling? (2) Under what conditions do AVVs produce intense secondary transient pressures during rapid pipe filling? (3) How sensitive are secondary transient pressures to the pipe profiles? (4) Can the induced secondary transient pressures result in column separation in other parts of the pipe systems? (5) To what extent can the secondary transient pressures be controlled by proper AVVs sizing? And (6), to what extent does the two-phase flow formed on the downstream side of AVVs affect the transient responses of pipe systems during rapid filling?

\section{Numerical model}

Malekpour et al. ${ }^{24}$ propose a shock fitting based model which can simultaneously account for both filling and column separation. In this research the model proposed by Malekpour \& Karney is extended to account for the air valve boundary condition. The proposed model solves the water hammer equations [equations (1) and (2)] on a dynamic finite difference mesh by the method of characteristics. Water column separation is included in the model by the well-known Discrete Gas Cavity Model (DGCM):

$$
\frac{\partial V}{\partial t}+g \frac{\partial H}{\partial x}+\frac{f}{2 D}|V| V=0
$$

$$
\frac{\partial H}{\partial t}+\frac{a^{2}}{g} \frac{\partial V}{\partial x}=0
$$

where $V=$ velocity $\left(\mathrm{ms}^{-1}\right), H=$ piezometric head $(\mathrm{m}), D=$ pipe diameter $(\mathrm{m}), a=$ elastic wave velocity $\left(\mathrm{ms}^{-1}\right), g=$ gravitational acceleration $\left(\mathrm{ms}^{-2}\right), f=$ friction factor in Darcy-Weisbach equation, and $x, t=$ distance and time independent variables respectively.

To facilitate development, consider Figure 1 which maps the computational cells for a given time line onto a hypothetical pipe system. Small gas cavities assumed in DGCM formulation are schematically shown as irregular ovals. It is seen that at a given time the two computational cells are completely filled but the third cell is in the process of being filled. As is discussed later, to satisfy numerical stability criterion, a tiny computational time step is required. This causes the water column front to advances incrementally during each time step. At the current computational time, the unknowns are the flow discharges entering and leaving each computational node, the piezometric head and volume of the gas cavity, and the water column advancement length äx In order to calculate unknowns at computational node $P 2$, the following equations can be written. These equations - taken in sequence - are discrete form of the continuity and momentum equations for the front cell, volume balance at the gas cavity, the equation of state of the gas cavity, and positive characteristic equation respectively:

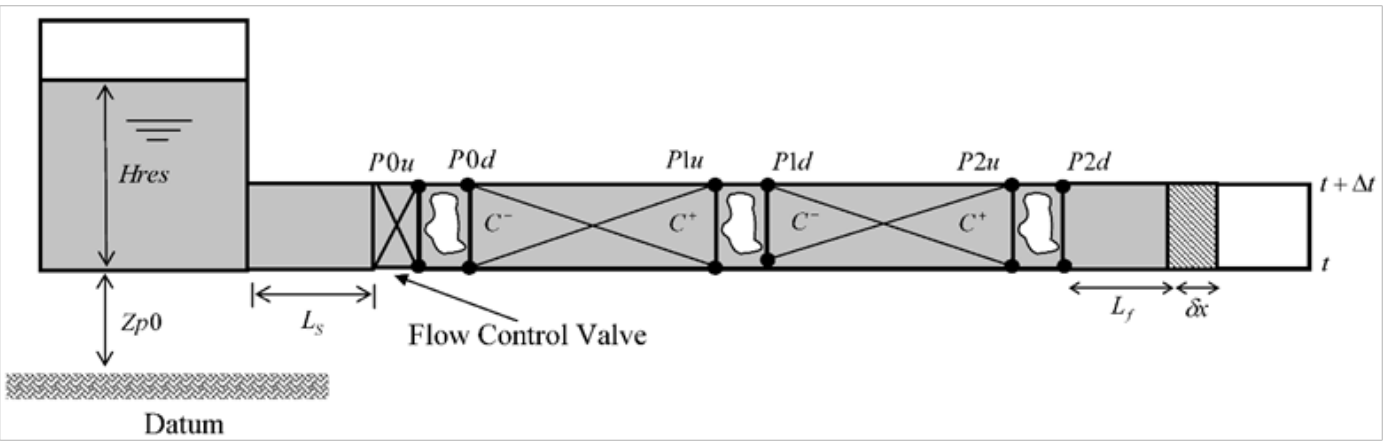

Figure I Typical computational cells at a given time.

$$
\begin{gathered}
\psi\left(Q_{P 2 d}\right)_{t+\ddot{A} t}+(1-\psi)\left(Q_{P 2 d}\right)_{t}-\frac{\delta x}{\Delta t}=0 \\
\frac{1}{A \Delta t}\left[\left(L_{f}+\delta x\right)\left(Q_{P 2 d}\right)_{t+\Delta t}-L_{f}\left(Q_{P 2 d}\right)_{t}\right]=\frac{1}{A^{2}}\left[\psi\left(Q_{p 2 d}\right)_{t+\ddot{A} t}^{2}+(1-\psi)\left(Q_{P 2 d}\right)_{t}^{2}\right]-g S_{0}\left(\psi \delta x+L_{f}\right) \\
-g \psi\left(H_{P 2 d}-Z_{P 2 d}\right)_{t+\ddot{A} t}-g(1-\psi)\left(H_{P 2 d}-Z_{P 2 d}\right)_{t}+g \psi\left(L_{f}+\delta x\right) S f_{t+\Delta t}+g(1-\psi) L_{f} S f_{t}
\end{gathered}
$$

$\left(\forall_{P 2}\right)_{t+\Delta t}=\left(\forall_{P 2}\right)_{t}+\left[\psi\left(Q_{2 d}-Q_{2 u}\right)_{t+\ddot{\mathrm{A}} t}+(1-\psi)\left(Q_{2 d}-Q_{2 u}\right)_{t}\right] \times \Delta t(5)$

$\left(\forall_{P 2}\right)_{t+\Delta t}=\frac{P_{0}^{*} \alpha_{0} \forall_{R}}{\rho g\left(H_{P 2 d}-Z_{P 2 d}-H_{V}\right)}$

$C^{+}:\left(H_{P 2 u}\right)_{t+\Delta t}=\left(H_{P 2 d}\right)_{t+\Delta t}=C_{1}-C_{2}\left(Q_{P 2 u}\right)_{t+\Delta 2}$

where $C_{1}$ and $C_{2}$ can be calculated as follows: ${ }^{26}$

$C_{1}=\left(H_{P 1 d}\right)_{t}+\frac{a}{g A}\left(Q_{P 1 d}\right)_{t} ; \quad C_{2}=\frac{a}{g A}+\frac{f \Delta x}{2 g D A^{2}}\left|\left(Q_{P 1 d}\right)_{t}\right| ; S f=\frac{f}{D} \frac{Q_{P 2 d}^{2}}{2 g A^{2}}$
In the above equations $Q_{P 2 u}, Q_{P 2 d}=$ discharge at the upstream and downstream side of the cavity at point $P 2$ respectively, $H_{P 2 u}=H_{P 2 d}$ $=$ piezometric head at the upstream and downstream side of the cavity at point $P 2$ respectively, $Z_{P 2 u}=Z_{P 2 d}=$ pipe elevation upstream and downstream side of cavity at point $P 2$ respectively, $Q_{P 1 d}=$ discharge at the downstream side of the cavity at point, $H_{P 1 d}=$ piezometric head at the downstream side of the cavity at point, $A=$ cross sectional area of the pipe, $D=$ pipe diameter, $\rho$ = water density, $L_{f}=$ water column length in the front cell in the previous time line, $\delta x=$ water 
column advancement in current time step, $\forall_{P 2}=$ cavity volume at point $P 2, H_{V}=$ gage vapour pressure head, $\alpha_{0}=$ initial void fraction, $\forall_{R}$ = computational cell volume, $P_{0}^{*}=$ reference pressure, $\Delta t=$ computational time step, $S_{0}=$ pipeline slope, $S_{f}=$ energy slope, $g=$ gravitational acceleration, $t, t+\Delta t=$ time indexes for the previous and current time lines respectively.

Equations (3) to (7) can be simultaneously solved to determine the unknowns, $Q_{P 2 u}, Q_{P 2 d}, H_{P 2 d}, \forall_{P 2}$, and $\delta x$. These nonlinear equations are solved here using the Newton-Raphson method. To calculate unknowns at point $P 1$, equations (5), (6), and (7) with appropriate indexing along with the negative characteristics equation [equation (8)] are considered.

$$
C^{-}:\left(H_{P 1 d}\right)_{t+\Delta t}=C_{3}+C_{4}\left(Q_{P 1 d}\right)_{t+\Delta t}
$$

where $C_{3}$ and $C_{4}$ can be calculated as follows ${ }^{26}$

$$
C_{3}=H_{P 2 u}-\frac{a}{g}\left(Q_{P 2 u}\right)_{t} \quad ; C_{4}=\frac{a}{g A}+\frac{f \Delta x}{2 g D A^{2}}\left|\left(Q_{P 2 u}\right)_{t}\right|
$$

By algebraic manipulation of equations (5), (6), (7), and (8) the following quadratic equation can be derived:

$$
\left(\left(H_{P 1 d}\right)_{t+\Delta t}-Z_{P 1 d}-H_{V}\right)^{2}+2 B_{1}\left(\left(H_{P 1 d}\right)_{t+\Delta t}-Z_{P 1 d}-H_{V}\right)-B_{4}=0
$$

The solution of the above algebraic equation is as follows.

$$
\left(H_{P 1 d}\right)_{t+\Delta t}-Z_{P 1 d}-H_{V}=-B_{1}\left(1+\sqrt{1+B_{B}}\right) \text { if } B_{1} \leq 0
$$

$$
\left(H_{P 1 d}\right)_{t+\Delta t}-Z_{P 1 d}-H_{V}=-B_{1}\left(1-\sqrt{1+B_{B}}\right) \text { if } B_{1}>0
$$

where

$$
\begin{aligned}
& B_{1}=B_{2} C_{4} C_{2} B_{V}+0.5\left(Z_{P 1 d}+H_{V}\right)-B_{2}\left(C_{2} C_{3}+C_{4} C_{1}\right) ; B_{B}=\frac{B_{4}}{B_{1}^{2}} \\
& B_{2}=\frac{0.5}{C_{2}+C_{4}} ; B_{V}=\frac{\left(\forall_{P 1}\right)_{t}}{\psi \ddot{\mathrm{A}} t}+\frac{1-\psi}{\psi}\left(Q_{P 1 d}-Q_{P 1 u}\right)_{t} ; B_{4}=\frac{P_{0}^{*} \alpha_{0} \forall_{R} B_{2} C_{4} C_{2}}{0.5 \rho g \psi \ddot{\mathrm{A}} t}
\end{aligned}
$$

In cases having large gas volumes and low pressure or small gas volume but high pressures, equations (10) or (11) may generate inaccurate results due to the radical. This occurs when $\left|B_{B}\right| \ll 1$ . The appropriate results in such cases can be achieved through the linearization of the original equations that results in the following equations ${ }^{26}$

$$
\begin{array}{ll}
\left(H_{P 1 d}\right)_{t+\Delta t}-Z_{P 1 d}-H_{V}=-2 B_{1}-\frac{B_{4}}{2 B_{1}} & \text { if } B_{1} \leq 0 \\
\left(H_{P 1 d}\right)_{t+\Delta t}-Z_{P 1 d}-H_{V}=\frac{B_{4}}{2 B_{1}} & \text { if } B_{1}>0
\end{array}
$$

Equations (12), and (13) are used if $\left|B_{B}\right|$ is small (less than 0.001 for example), otherwise equations (10) and (11) are utilized. Having $H_{P 1 d}$ calculated, other unknowns, $Q_{P 1 u}, Q_{P 1 d}$, and $\forall_{P 1}$ can be easily obtained by equations (5), (7), and (8).

In order to obtain unknowns at boundary point, $P_{0}$, equations (5), (6), (8) with appropriate indexing and equation (14) which is the energy balance between the reservoir and point $P_{0 u}$ are simultaneously solved by the Newton-Rapshon method:

$$
\frac{1+K_{V}+K_{S}}{2 g A^{2}}\left(Q_{P 0 u}\right)_{t+\Delta t}^{2}+\left(H_{P 0 d}\right)_{t+\Delta t}+\frac{L_{S}}{A g}\left(\frac{\left(Q_{P 0 u}\right)_{t+\Delta t}-\left(Q_{P 0 u}\right)_{t}}{\Delta t}\right)-Z_{P 0 u}-H_{r e s}=0
$$

where $K_{V}=$ valve head loss coefficient, $L_{S}=$ the length of water column between the valve and reservoir, $H_{r e s}=$ reservoir height, and $K_{s}=\frac{f L_{S}}{D}$.

This computational procedure can be used until the water column fills the front cell completely. A cell is then added to the computational grid so that the same procedure can again be employed. It should be noted that as the water column fills each pipe completely, an additional internal boundary condition arises which could be either a junction or an AV. Junction boundary conditions are modeled with the same approach presented for the intermediate nodes with the only difference that the positive and negative characteristic equations pick-up the information from the upstream and downstream pipes respectively rather than a single pipe as in intermediate nodes. Computational time step is determined based on the Courant-Friedrich-Lewy (CFL) criterion. ${ }^{26}$

\section{Air valve boundary condition}

The state of the art in air valve modeling is first considered. In this method, the air valve boundary equations are developed based on the following assumptions ${ }^{4,26}$ (1) air enters and leaves the pipe under isentropic flow conditions; (2) the air admitted to the pipe remains near the valve; and (3) the volume of the air is small compared to the pipe line reach. To numerically represent air valve boundary conditions, the conditions under which the valve may be activated must be articulated. Figure 2 shows two possible conditions under which air valves may perform. In the first condition (Figure 2) the water column front is in the first computational cell of the pipe leaving the air valve while in the second condition both the computational cells on either side of the valve are completely filled. Since the numerical representation of the air valve boundary condition is different in each condition, they are discussed separately. In the first condition, five boundary unknowns which are the inflow discharge to the boundary node, $Q_{P n+1}$, the outflow discharge from the boundary node, $Q_{P 0}$, the piezometric head at the boundary node, the air pocket volume $\forall_{a}$, and the water column advancement, $\delta x$ can be calculated for the current timeline by simultaneous solution of discrete form of the continuity and momentum equations for the front cell [equations (3), and (4)], positive characteristic equation [equation (7)], and the following equations which are, conservation of mass at the air valve location, and air equation of state respectively.

$$
\begin{aligned}
& \left(\forall_{a}\right)_{t+\Delta t}=\left(\forall_{a}\right)_{t}+0.5 \Delta t\left[\left(Q_{P 0}-Q_{P n+1}\right)_{t+\Delta t}+\left(Q_{P 0}-Q_{P n+1}\right)_{t}\right] \\
& P_{\text {air }}\left(\forall_{a}\right)_{t+\Delta t}=\left[m_{t}+\Delta t\left(\dot{m}_{t}+\dot{m}_{t+\Delta t}\right)\right] R T \\
& P_{\text {air }}=\rho g\left(\left(H_{P n+1}\right)_{t+\Delta t}-Z_{P n+1}+H_{a t m}\right)
\end{aligned}
$$


where $m_{t}=$ initial mass of the air pocket, $\dot{m}_{t}=$ initial rate of the air mass flow into or out of the air pocket, $\dot{m}_{t+\Delta t}=$ final rate of the air mass flow into or out of the air pocket, $R=$ gas constant, $T=$ absolute temperature, $P_{\text {air }}=$ air absolute pressure, and $H_{\text {atm }}=$ atmospheric pressure head.

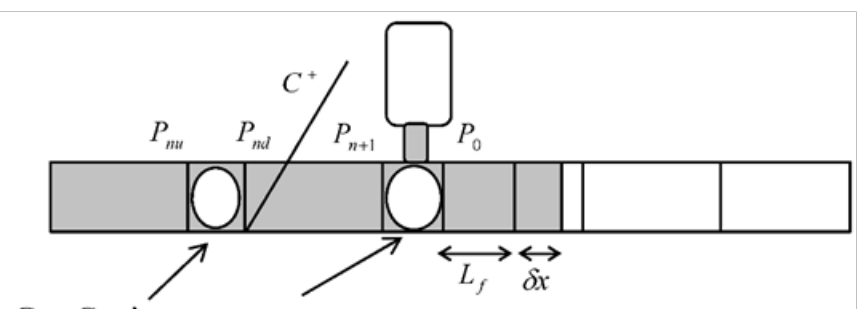

Gas Cavity Air Pocket

(a)

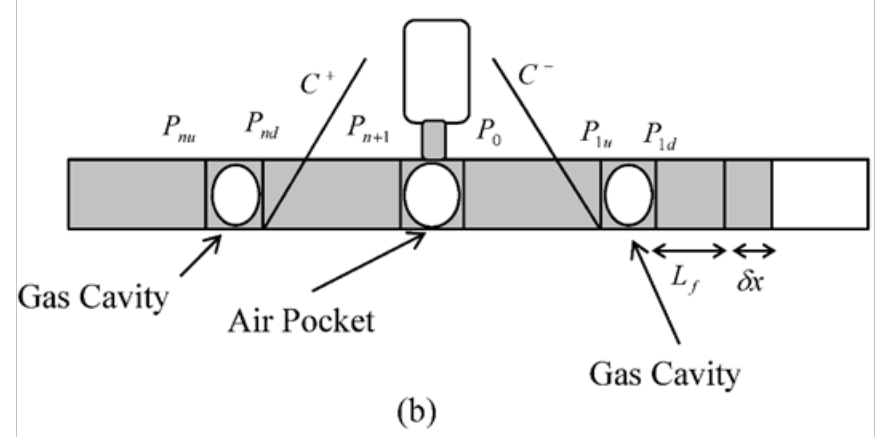

Figure 2 Air valves in different computational conditions.

Depending on if the air mass flow into or out of the valve is either sonic or subsonic it can be calculated by the well-known equations presented in the literature ${ }^{26}$ For details see the appendix. For the second condition shown in Figure 2, the unknowns can be obtained through simultaneous solution of equations (15), and (16), along with positive and negative characteristics equations (7), and (8). In both conditions resulting equations are solved by using the NewtonRaphson method.

The assumptions made in deriving air valve boundary equations are usually acceptable under conventional transient events that usually occur in fully pressurized pipe systems. However, the assumption that the volume of the air is small compared to the pipeline reach is unlikely to be satisfied (or, in practice, checked) during rapid filling condition in which a bulk mass of air spreads over a long distance of the pipe downstream side of the air valve. In such conditions, open channel flow is established beneath the air pocket and extended to the downstream side as more air admitted to the pipe.

The complex resulting two-phase flows may be resolved by a 3D two-phase flow CFD analysis. However, such models are still usually too computationally expensive to be practical in the context of large scale pipe systems. Thus, 1D models which can treat mixed flow in pipe systems are still attractive. However, existing models need more improvement in order to fit into the following context as they mostly suffer from numerical instability in the typical range of pipe acoustic wave velocity. ${ }^{27}$ Since the model proposed here still does not support mixed flow, the air valve boundary equations are adjusted to account for two features of the expected two-phase flow. First, when considerable air volumes are present, the model considers the significant head loss generated both in open channel section and at the location where the open channel flow switches to pressurized flow through a hydraulic jump. ${ }^{28}$ Second, a moving boundary is used between the open channel and pressurized zone, an apparently small feature but one that significantly affects the dynamics of the downstream water column. Figure 3 schematically shows how the head loss and boundary movement are dealt with in the proposed boundary condition. All the equations representing the proposed air valve boundary condition are exactly similar to those presented before, but in the proposed method as the air pocket size exceeds the size of a computational cell the downstream boundary, separating the open channel region from the pressurized one, is shifted forward by one cell and the associated negative characteristics equation picks up its required data from the subsequent computational node. In this case, the piezometiric head at the moving boundary is considered equal to the elevation of the pipe at this point plus the air pressure head. This assumption sets the slope of the hydraulic grade line (HGL) in the two-phase flow region equal to the pipe slope. Experiments show that this is a reasonable assumption. ${ }^{28}$ In the case where the air pocket shrinks, the boundary point is shifted backward by one cell as the air pocket size decreases by an amount equal to the size of one computational cell.

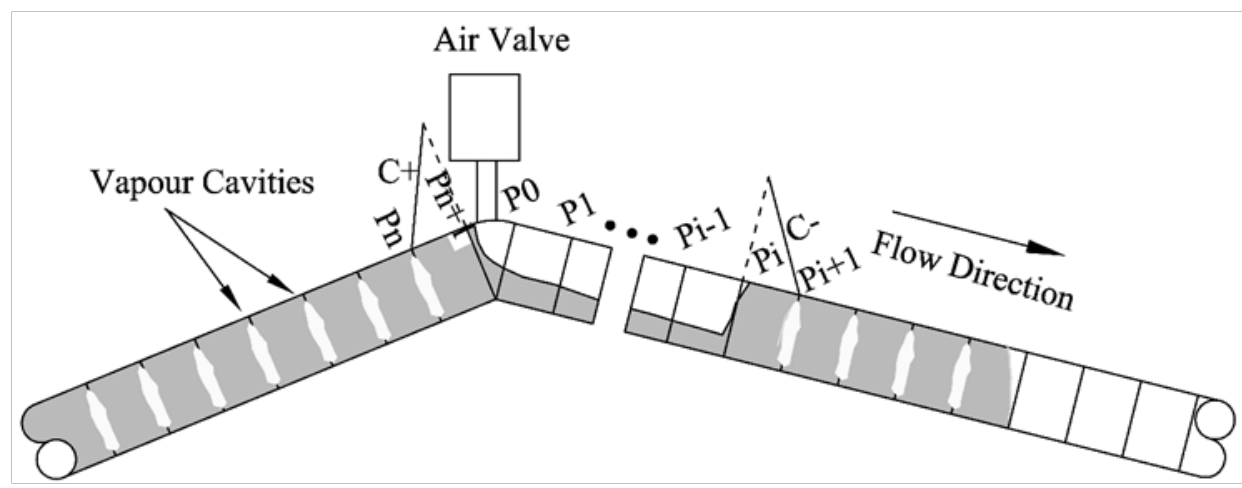

Figure 3 schematic flow condition downstream sides of the AVVs.

\section{Model validation}

The hydraulic features of the proposed model were previously validated through comparing the model results with the experimental data presented by Liu et al. ${ }^{22}$ demonstrating excellent agreement between experimental and numerical results. ${ }^{11,24}$ Model outcomes were also compared to the results obtained from a Smoothed Particle Hydrodynamics (SPH) model by $\mathrm{Hou}^{29}$ again with excellent agreement. 
Due to the lack of experimental data, the column separation features of the model were tested indirectly ${ }^{25}$ by employing the experimental data presented by Bergant et al., ${ }^{18}$ again good agreement was observed between the model and the experiment.

Unfortunately, no ideal validation data is available of the hydraulic responses of the proposed air valve boundary condition (PAVB). In lieu of this, the validity of the model results is indirectly examined by the aid of a hypothetical example whose final steady state solution is analytically available. Figure 4 depicts a gravity pipe system consisting of three pipes with the lengths of 300,200 , and $50 \mathrm{~m}$ respectively, all with diameter $500 \mathrm{~mm}$, wave velocity $1000 \mathrm{~m} / \mathrm{s}$ and Darcy-Weisbach friction factor 0.016. A constant water level reservoir with a height of $3 \mathrm{~m}$ feeds the system at the upstream side. The pipeline profile is intentionally selected in such a way that the flow in the system converges to different steady state conditions depending on whether or not an AVV is installed at knee point A.

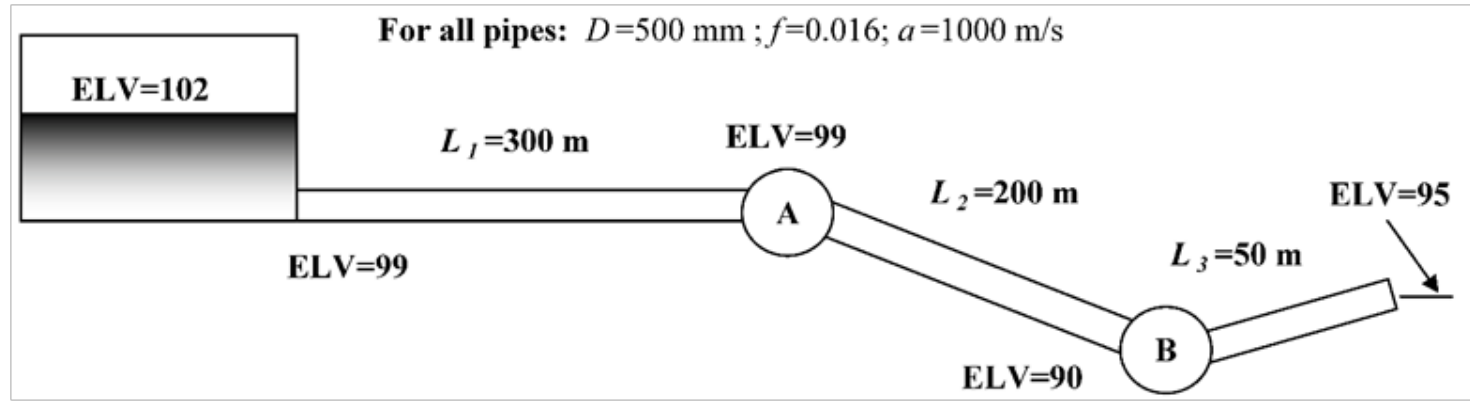

Figure $4 \mathrm{~A}$ hypothetical pipe system for validating purpose.

Rapid filling is simulated in the pipe system for three different cases: (1) No AVV at point A; (2) AVV at point A with conventional air valve boundary condition (CAVB); (3) AVV at point A with PAVB. In all three cases when the water column reaches the end of the pipe, the time marching is continued with fixed computational domain until the transient flow is completely removed and steady state flow is established in the system. Figure 5 depicts the resultant steady state HGLs for the three cases. In the absence of the AVV the steady state flow discharge converges to $0.522 \mathrm{~m}^{3} \mathrm{~s}^{-1}$, confirmed by spreadsheet calculations. In this case, the HGL falls below the pipe profile producing negative pressure at A. The AVV admits air at point A and reduces the final steady state discharge. In this case the magnitude of the steady state discharge is dominated by the characteristics of that part of the pipe system upstream of point A. Since the pressure at point A remains near atmospheric, the driving head is reduced, causing that the steady state discharge of the system to reduce as well. Obviously, the discharge will thus not achieve full flow in downstream system because available driving head is greater than the head required for carrying the flow discharge under fully pressurized condition. The result is that the system dissipates the extra head by generating high velocity open channel flow on the downstream side of point A. The open channel flow then reverts to pressurized flow at a location where the pipe elevation provides the energy necessary for pushing the flow through the downstream system.

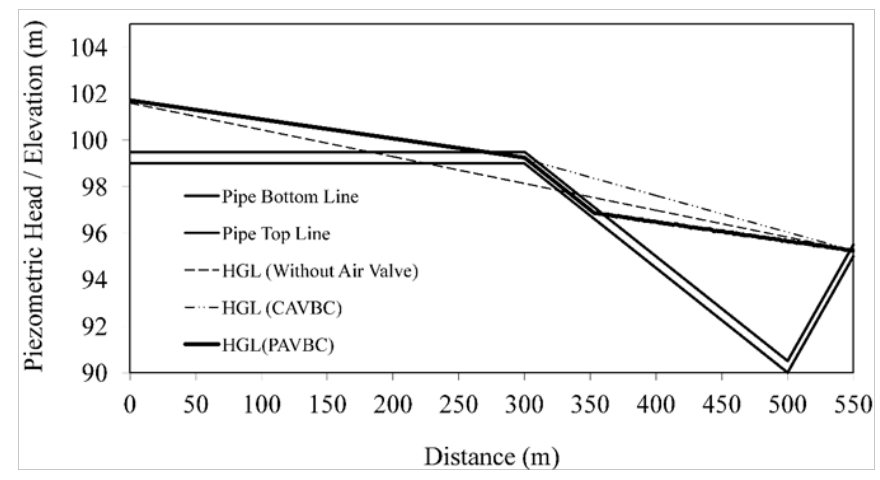

Figure 5 Steady state results for different scenarios.
As shown in Figure 5, the model with the CAVB fails to converge to an exact solution and the HGLs on either side of point A have different slopes. Although the discharge on the upstream side of the air valve converges to exact steady state discharge, $0.441 \mathrm{~m}^{3} / \mathrm{s}$, the flow in the downstream side converges to a larger discharge, $0.610 \mathrm{~m}^{3} / \mathrm{s}$. This means that the whole system never reaches a single steady state and the air pocket grows continually.

Figure 5 also demonstrates that the model with the PAVB converges to exact steady state discharge and properly replicates head losses in the open channel zone. To further investigate the validity of the model, the pipe system is independently modeled with program SWMM. ${ }^{30}$ Numerical results show that the final steady state solution captured by SWMM (Figure 6) is in excellent agreement with that obtained from the proposed model.

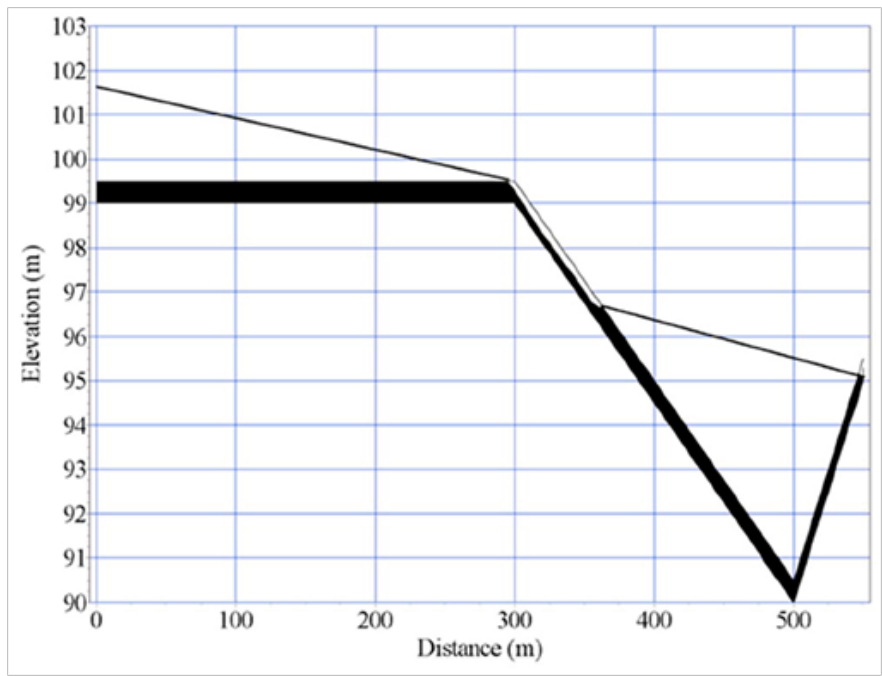

Figure 6 Steady state flow condition captured by SWMM.

Figure 7 \& Figure 8 compare the transient responses of the system obtained from SWMM, with those obtained from the model with both CAVB and PAVB at two different locations (150 and 205m downstream side of point A respectively). As can be seen, the transient 
responses captured by the model with the PAVB are in good agreement with those obtained from SWWM, while the model with the CAVB produces erroneous responses.

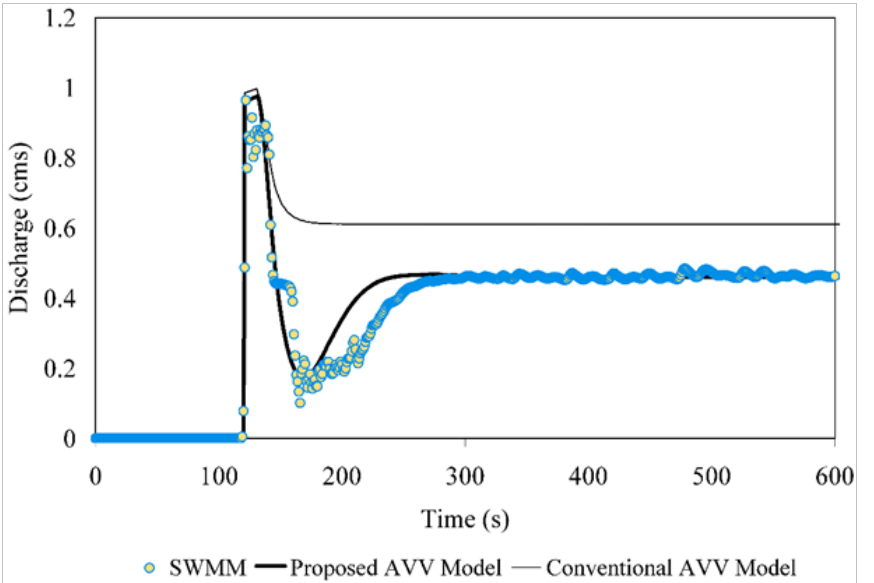

Figure 7 Transient responses of the system at $150 \mathrm{~m}$ downstream side of AVV.

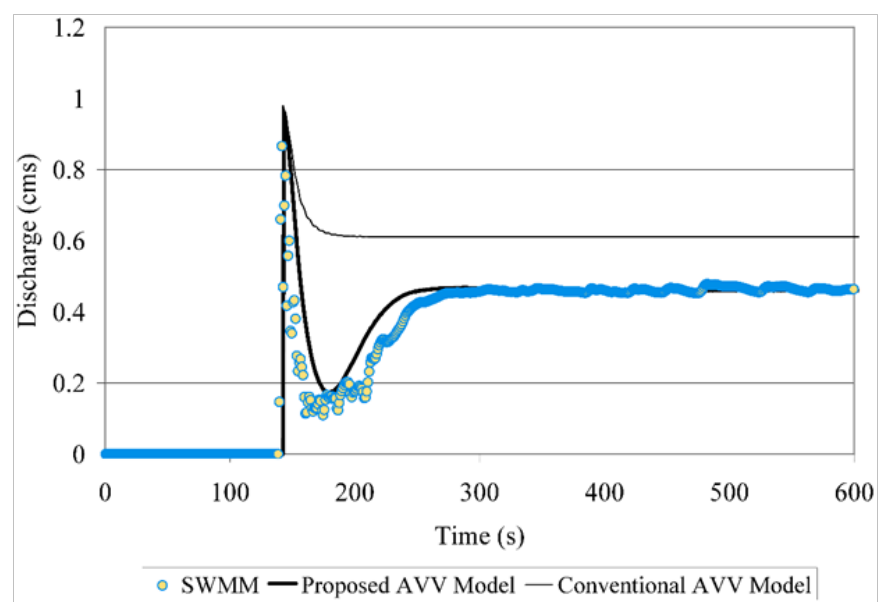

Figure 8 Transient responses of the system at $205 \mathrm{~m}$ downstream side of AVV.

\section{Transient simulation results}

To examine how AVVs affect the transient responses of pipe systems, rapid filling is numerically performed in a hypothetical pipe system with and without an AVV. Another hypothetical pipe system should be utilized here as the pipe system in the previous section cannot give rise to column separation. Such a system provides a good context for exploring the roles of AVVs in protecting pipe systems against negative pressures and column separation. Figure 9 depicts a typical undulating pipe system possessing such characteristics. The system consists of a reservoir, three pipes each having different lengths of 40001000 and $700 \mathrm{~m}$ respectively all again with diameter $500 \mathrm{~mm}$ and wave velocity $1000 \mathrm{~m} / \mathrm{s}$ but with a friction coefficient of 0.024 . Key elevations are also shown. Rapid filling is simulated for two different cases, hereinafter called Case 1 and Case 2 for short. In Case 1 the pipe system contains no AVV while in Case 2 an AVV functions at the knee point A. Both the inlet and outlet orifice sizes of the AVV are calculated as $100 \mathrm{~mm}$ based on the standard conventionally used in practice $^{31}$

Numerical results show that in Case 1 column separation occurs at point A which induces an extreme water hammer pressure. Figure 10 depicts the piezometric head and vapour cavity volume time history at point A. As can be seen, following the collapse of the cavity a pressure head spike with the magnitude of around $110 \mathrm{~m}$ occurs at point A propagating along the system. As demonstrated before ${ }^{24}$ the 'V-shaped' pipe profile following point A assists in the formation and collapse of the cavity during rapid filling. It is also found that the first pressure spike may induce column separation in other locations. Numerical results show that in the current pipe system the first pressure spike induces a major column separation at a point located $2500 \mathrm{~m}$ upstream of point A. The secondary column separation is attributed to the reflection of the first pressure spike at the upstream reservoir causing negative pressures in the first pipe. Figure 11 shows the formation and collapse of the vapour cavity at this point. As can be seen, the secondary pressure spike with the magnitude of about $60 \mathrm{~m}$ occurs following the cavity collapse which then propagates to other parts of the system. Reflection of this pressure spike, as marked by a circle on Figure 10, appears at point A soon after.

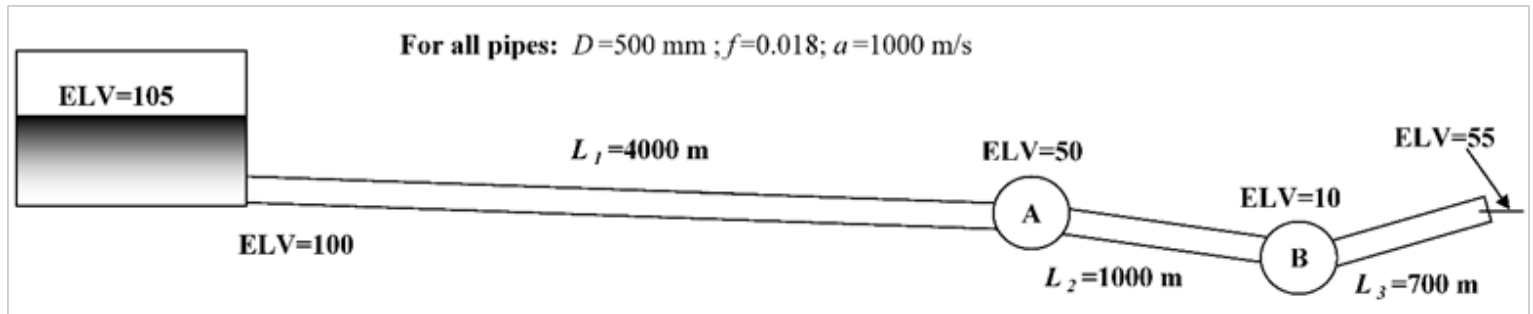

Figure 9 Schematic of the hypothetical pipe system.

To examine how AVVs affect rapid filling hydraulics, the model results for Case 2 are considered. Figure 12 depicts the air pocket volume and piezometric head time history at knee point $\mathrm{A}$ in this case. It can be seen that following collapse of the air pocket an extreme pressure spike with almost the same magnitude of the pressure spike induced in Case 1 (about 110m) is onset. Similar to Case 1, in Case 2 the first pressure spike induces column separation somewhere in the first pipe, located $2500 \mathrm{~m}$ upstream side of the knee point. Figure 13 depicts the piezometric head and cavity collapse at this point. As can be seen, the position and magnitude of the pressure rise are almost similar to those in Case 1. Interestingly, although the AVV prevents the occurrence of column separation during rapid pipe filling, it induces almost the same detrimental effects. The similarity in the transient responses can be better highlighted by comparing the envelope of the maximum and minimum piezometric heads induced in Case 1 and Case 2 (Figure 14). As can be seen in both cases the magnitude and distribution of the positive and negative pressures along the pipe are almost similar.

Although the term 'column separation' is conventionally used when a vapour cavity separates the adjacent water columns, the presence of an air pocket can also produce a column separation with similar response during rapid pipe filling. Nevertheless, the formation, evolution and collapse of the vapour cavity and the air pocket can be 
quite different depending on how the air valve restricts the air flow at the knee point. To better understand the similarities and differences, the sequence of events in Case 2 from air pocket formation to collapse are compared with their counterparts in Case 1.

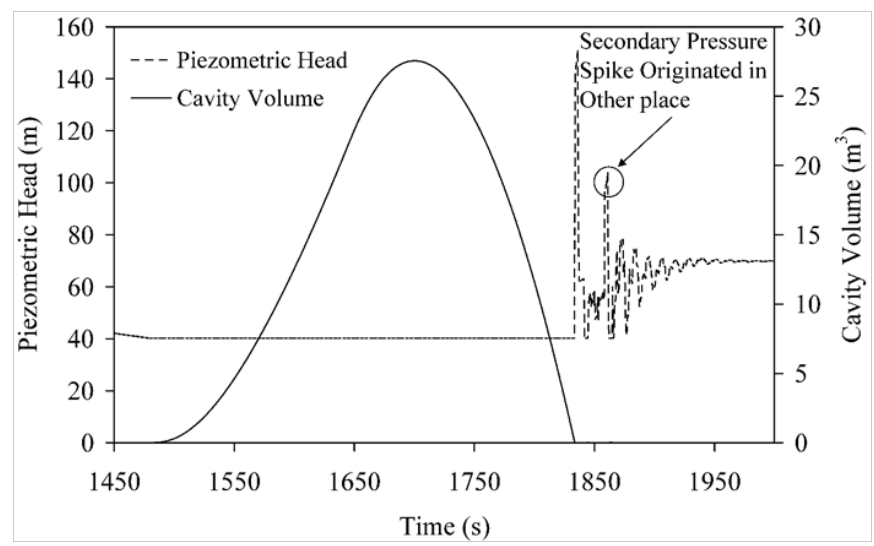

Figure 10 Cavity and pressure head time history at point A.

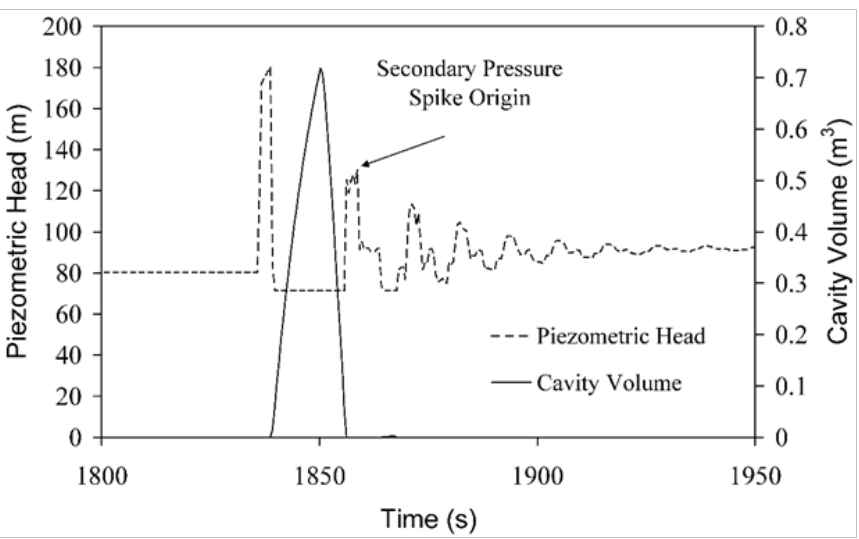

Figure I I Cavity and pressure head history at $2500 \mathrm{~m}$ upstream side of the knee.

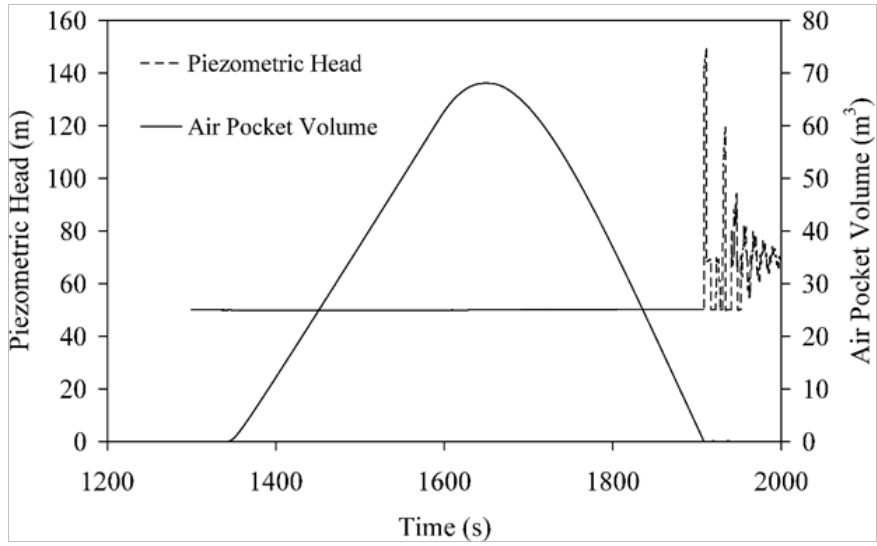

Figure 12 Piezometric head and air pocket volume history at air valve location.

Figure 15 shows that as the water column front passes the high point negative pressures tend to setup at this point. In Case 1 no vapour cavity is formed until the pressure at the knee point reaches the vapor pressure, but in Case 2 the AVV immediately starts admitting air to the pipe as soon as the piezometric head slightly drops below the high point's elevation. This causes that stages 1 and 2 in Case 1 are represented only by one stage in Case 2 .

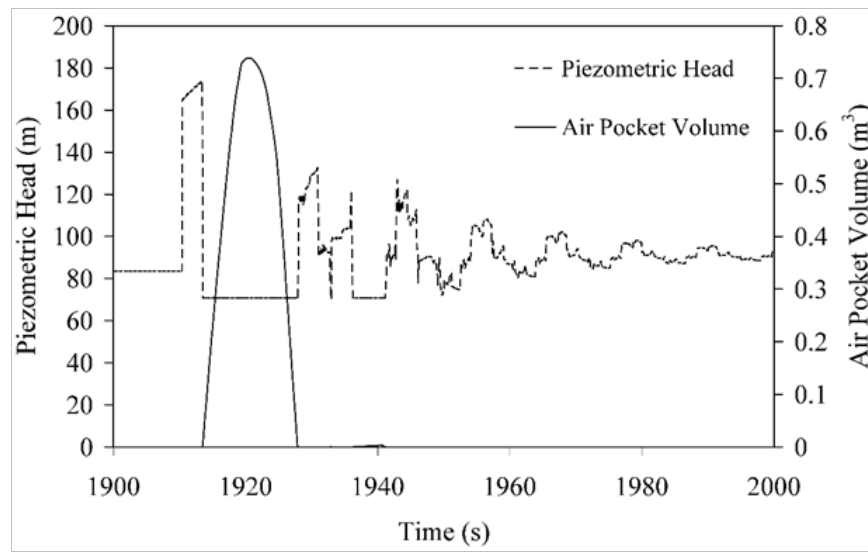

Figure 13 Cavity and pressure head history at $2500 \mathrm{~m}$ upstream side of the knee point.

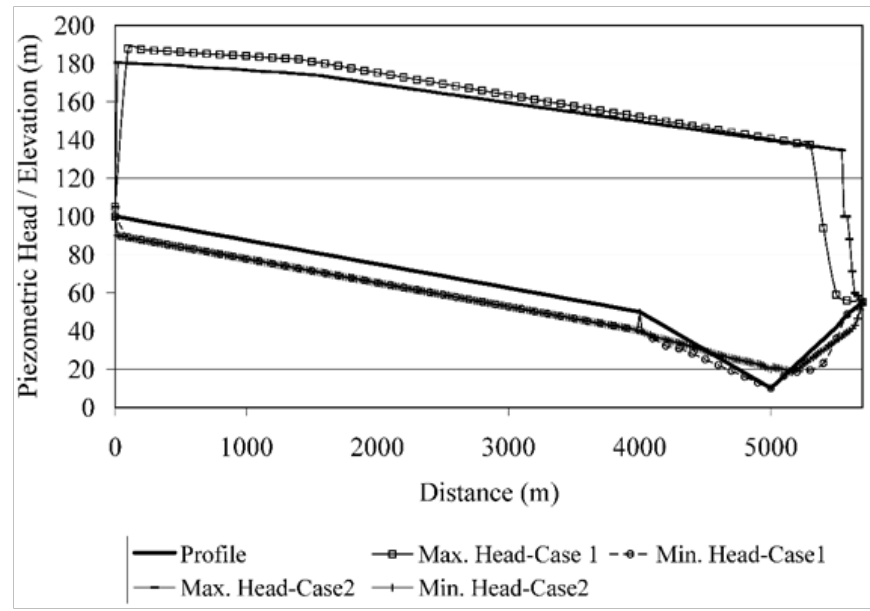

Figure 14 Envelopes of Max and Min piezometric head.

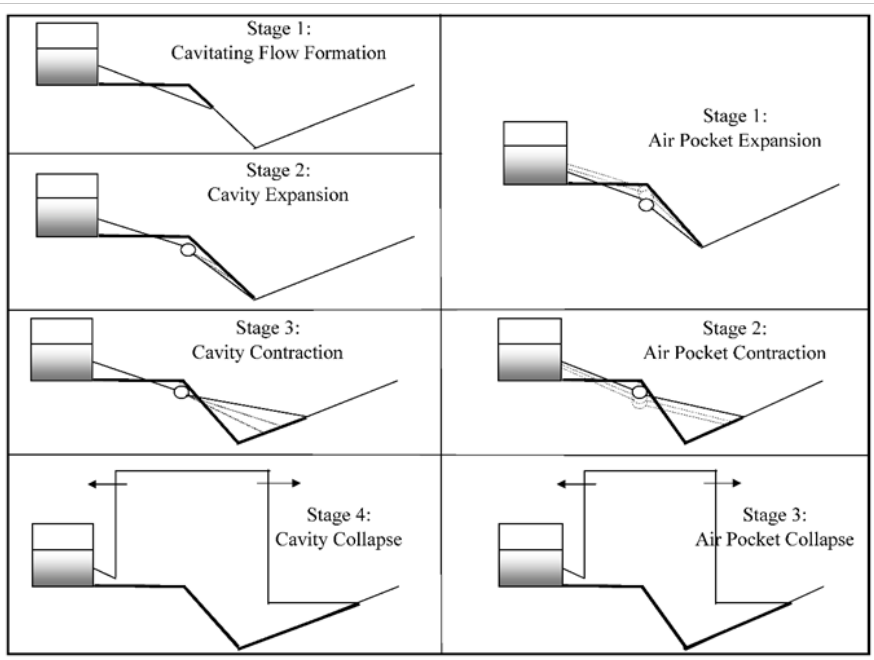

Figure I 5 Filling procedure stages: left- without air valve; right- with air valve.

Vapour cavity expansion in Case 1 is caused by a mass imbalance produced soon after the pressure at the high point becomes fixed at the vapour pressure. In this stage, the inflow to the vapour cavity remains constant since the constant pressure at the high point causes the upstream HGL slope to remain constant. However, the outflow from the vapour cavity increases as the water column further descends the second pipe and as its associated HGL becomes steeper. 
In Case 2, as the water column descends further along the second pipe, and the HGL on the downstream side of the high point becomes steeper while the variations of the HGL's slope on the upstream side of the knee point depends on how the AVV restricts air flow into the system. If the AVV's orifice is large enough, extensive air intrusion causes the pressure at the high point to remain almost atmospheric in such a way that the upstream HGL's slope remains almost constant like in Case 1. However, for smaller orifice sizes, the pressure continually drops at the knee point because the AVV fails to provide required air flow. In such cases, since both the HGLs on the upstream and downstream of the knee point become steeper, a significant mass imbalance cannot be produced at the knee point, and thus the air pocket cannot grow significantly.

The vapour cavity expansion stage is completed when the water column ascending the third pipe decelerates to a level at which the outflow from the vapour cavity equals its inflow; at this moment the HGLs on the either side of the vapour cavity possess the same slope. As the water column ascends the third pipe, the HGL downstream of the knee point moderates while that on the upstream side of the knee point is maintained. The induced flow imbalance at the knee point results in vapour cavity contraction. If the AVV orifice is large enough, a quite similar sequence of events occurs in Case 2 through which the AVV continually expels the air out of the system while the air pressure at the high point remains almost atmospheric. However, for smaller orifices, since the AVV restricts the air releases, the pressure at the high point increases and the upstream HGL slope becomes flatter. It is seen that in the cavity contraction stage the vapour cavity limits hydraulic communication between separated water columns while in the air contraction stage, depending on the degree of compression of the air, the hydraulic information on the downstream side of the air pocket can be partly transmitted to the upstream side. Obviously, better communication causes the upstream water column velocity to be more in accordance with that on the downstream side of the knee point. When the vapour cavity finally collapses the adjacent water columns with different velocities suddenly rejoin. Water column rejoining similarly occurs in Case 2 when the air is completely removed from the system. Depending on both the velocity difference between the adjacent water columns and the magnitude of the pipe acoustic velocity, a huge pressure spike may be initiated by the collision of the two water columns.

To better understand the performance of AVVs during rapid pipe filling, further numerical exploration is performed with the system shown in Figure 9. To examine the influence of profile shape on the performances of AVVs, different scenarios are examined by changing the elevation at point $\mathrm{B}$. The scenarios are numerically tested by using both CAVB and PAVB in order to investigate how the two-phase flow established in the downstream side of AVVs affect filling hydraulics. Throughout this numerical exploration, the size of the AVV's orifices is intentionally selected large enough to keep the air pressure near atmospheric during filling. Table 1 compares the models' results under the performance of both CAVB and PAVB for various elevations at point B. It is seen that as point B's elevation reduces air intrusion increases in both cases with almost the same pattern. This can be explained by considering that regardless of the elevation of point B, the pressure at the high point remains almost constant at atmospheric whereby the flow feeding the high point remains constant with the maximum velocity of $2.72 \mathrm{~m} / \mathrm{s}$ (Table 1 ). On the other hand, by decreasing the elevation of point $\mathrm{B}$, the slope of the descending pipe leg increases causing that the downstream water column further accelerates and gains higher velocity. This clearly explains that, as the elevation of point $\mathrm{B}$ decreases, a greater flow imbalance is set up at the knee point whereby air intrusion increases.

Table I Numerical exploration results for both CAVB, and PAVB

\begin{tabular}{|c|c|c|c|c|c|c|c|c|c|c|}
\hline \multirow[t]{2}{*}{ ELV. B (m) } & \multicolumn{2}{|c|}{ Max head (m) } & \multicolumn{2}{|c|}{ Air volume (m3) } & \multicolumn{2}{|c|}{ Up velocity $(\mathrm{m} / \mathrm{s})$} & \multicolumn{2}{|c|}{ Down velocity $(\mathrm{m} / \mathrm{s})$} & \multicolumn{2}{|c|}{ Max velocity $(\mathrm{m} / \mathrm{s})$} \\
\hline & CAVB & PAVB & CAVB & PAVB & CAVB & PAVB & CAVB & PAVB & CAVB & PAVB \\
\hline 10 & 214 & 147.3 & 89.2 & 88.1 & 2.72 & 2.72 & -0.27 & I & 4.65 & 4.64 \\
\hline 15 & 203 & 148.6 & 78.8 & 79.2 & , & ” & 0 & 0.97 & 4.35 & 4.35 \\
\hline 20 & 186 & 149.6 & 65.6 & 68 & , & , & 0.27 & 0.96 & 4.03 & 4.02 \\
\hline 25 & 165 & 148.2 & 49.1 & 53.9 & ” & , & 0.68 & 0.98 & 3.68 & 3.68 \\
\hline 30 & $|4|$ & 136.7 & 32 & 35.2 & ” & " & 1.12 & 1.19 & 3.29 & 3.29 \\
\hline 35 & 99.5 & 99.6 & 8.5 & 8.9 & , & , & 1.86 & 1.86 & 2.86 & 2.86 \\
\hline 40 & \multicolumn{10}{|c|}{ No Air Intrusion } \\
\hline
\end{tabular}

Table 1 further shows that, in the CAVB case, higher air intrusion produces more intensive water column rejoining which in turn results in stronger water hammer pressures. This is because the larger air pockets provide more opportunity for the water column to further decelerate in the ascending pipe leg of the system and to reach lower velocity before rejoining the upstream water column. Table 1 also represents the downstream water column velocity just before the water column rejoinder ("Down Velocity"). It confirms that the lower point A's elevation, the lower the downstream water column velocity. In the PAVB case, the secondary water hammer pressures increase as the air pocket size increases, but beyond a particular point the magnitude of the induced secondary pressure becomes insensitive to the air pocket size. This response can be explained by considering that first in this case the water column on the downstream side of the AVV does not decelerate as much as it does in the CAVB case and second the water column velocity decelerates to almost a constant value independent of point B's elevation, both resulting in the water columns rejoining with lesser velocity difference. The dramatic difference between the responses of the system in CAVB and PAVB cases is attributed to the formation of the two-phase flow in the descending pipe which can be captured just by PAVB. The underlying physics causing such different responses are explained in the next section where the sequence of events during the deceleration of the water column in the ' $V$ '- shaped profile is discussed for both CAVB and PAVB.

Clearly large orifice sizes can prevent column separation but they do so by admitting extensive amounts of air. However, such large size orifices can themselves produce a column separation and rejoining 
like phenomenon which in turn results in significant secondary transient pressures and column separation in the system. This shows that the conventional sizing of AVVs which considers the same size for both the inflow and outflow orifices cannot provide a safe operational condition during pipe rapid filling. To prevent extreme secondary transient, the size of the AVV's outflow orifice should be carefully selected. Smaller orifices result in more air compression and better communication between the water columns on the upstream and downstream sides of the AVVs. Table 2 summarizes the maximum transient pressure heads induced at the AVV location for different sizes of the AVV's outflow orifice. As can be seen, reducing the size of the orifice down to $60 \mathrm{~mm}$ doesn't affect the magnitude of the induced water hammer pressure because they are all too big to produce sufficient air compression during filling. However, further size reductions do decrease the water hammer pressures. It is seen that the orifice's size of $10 \mathrm{~mm}$ results in a maximum piezometric head of $72.2 \mathrm{~m}$ which exceeds the final steady state piezomeric head at valve location $(69.76 \mathrm{~m})$ just less than $2.5 \mathrm{~m}$. Figure 16 demonstrates the AVV's dynamic behavior in this case. It is seen that the restriction made by the small orifice considerably increases the air release time whereby the adjacent water columns reach almost the same velocity before rejoinder. Figure 17 depicts the envelope of the maximum and minimum piezometric heads induced during rapid filling. It is seen that the ideal AVV choice effectively eliminates the adverse effects associated with water column rejoining. Finally the proposed air valve can account for air binding and the resulting reduction of the conveyance capacity of the system occurring when the steady sate flow is finally established. Figure 18 compares the time variation of the discharge of the system and the volume of the entrapped air for two different outlet orifices, $100 \mathrm{~mm}$ and zero.

Table 2 Maximum piezometric heads at the AVV location

\begin{tabular}{ll}
\hline Orifice size $(\mathbf{m m})$ & Piezometric head $(\mathbf{m})$ \\
\hline 100 & 147.3 \\
80 & 147.3 \\
60 & 147.3 \\
40 & 112.6 \\
20 & 80.4 \\
10 & 72.2
\end{tabular}

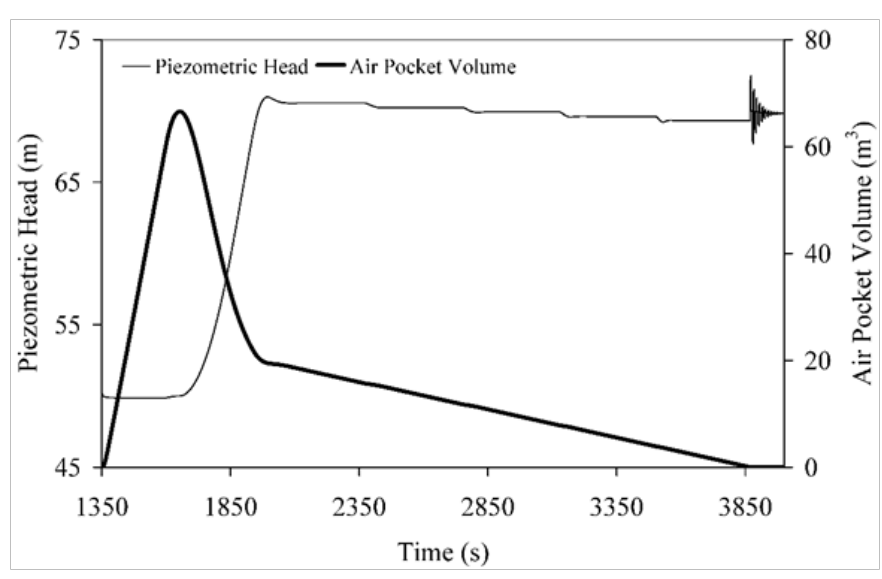

Figure 16 Piezometric head and air pocket volume time history for orifice size $=10 \mathrm{~mm}$.

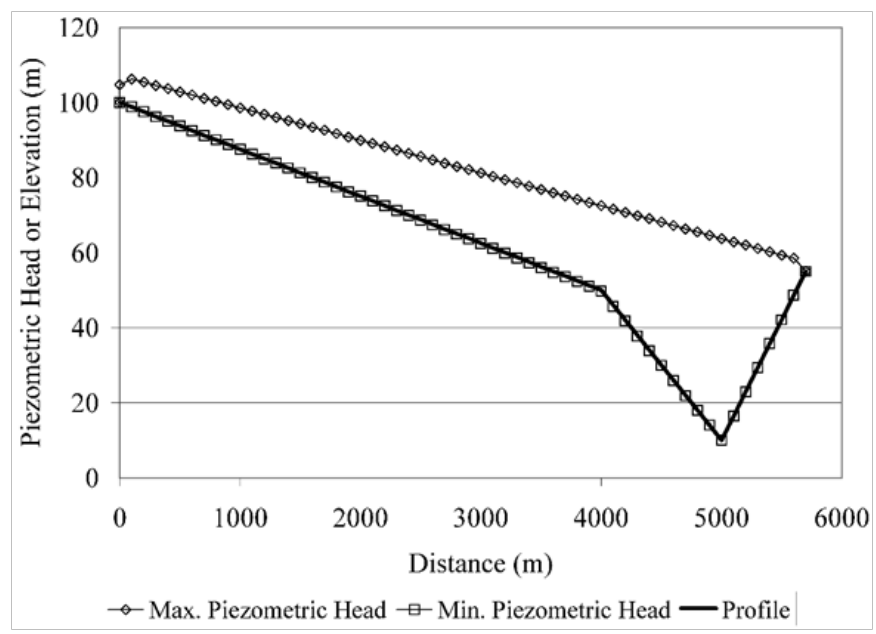

Figure 17 Envelope of Max and Min piezometric head for orifice size $=10 \mathrm{~mm}$.

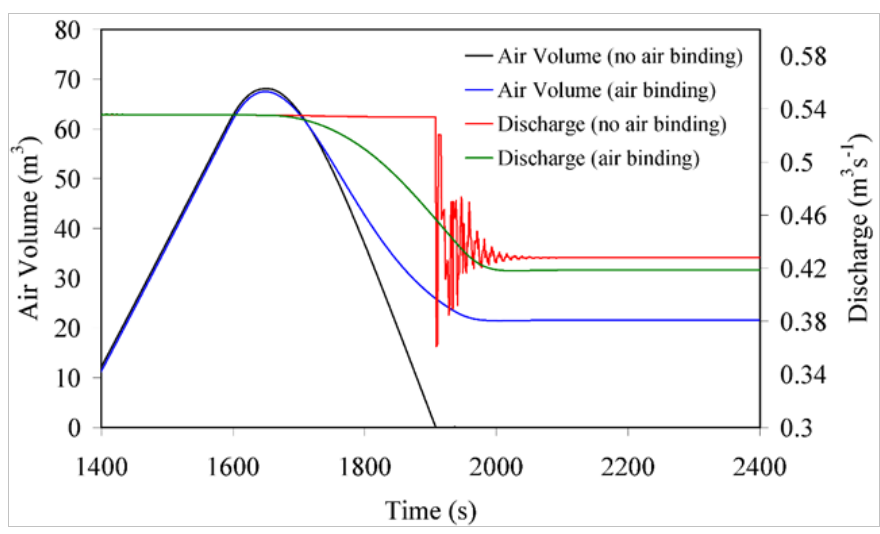

Figure 18 Time history of flow discharge for orifice sizes of $100 \mathrm{~mm}$ and zero.

As can be seen in Figure 18 following total removal of the air, the system reaches a steady state flow of $0.43 \mathrm{~m}^{3} / \mathrm{s}$. However if the air is not allowed to escape (by setting air valve's outflow orifice size $=0$ ), as shown in Figure 18, the discharge converges to a slightly lower discharge, $0.42 \mathrm{~m}^{3} / \mathrm{s}$. In this case the remaining entrapped air is finally compressed to a size of around $20 \mathrm{~m}^{3}$. This air pocket is stretch out in pipe 2 and produces an additional head loss of around $1.5 \mathrm{~m}$. It is worth noting that since in this particular example the induced head loss is not significant compared to the total head loss of the system, the consequent reduced discharge is thus not significant.

\section{Discussion}

As numerically examined, CAVB and PAVB can each produce different transient responses for exactly the same pipe system during rapid filling. The numerical results show that the CAVB can potentially produce much more severe transient pressures than the PAVB. In the CAVB case, larger air pocket sizes can provide an increased time for the downstream water column to decelerate (even negative), while in the PAVB case regardless of the size of the air pocket the downstream water column cannot decelerate to lower than a particular velocity.

In order to reveal how considering the key features of the resulting two-phase flow could produce such a tremendous difference between these two approaches, it is important to understand the key differences of the mechanisms under which the water columns decelerate in each case. To this end, the sequence of the events through which the water 
column fills the ' $\mathrm{V}$ '-shaped profile in the aforementioned example is compared for these two approaches. Figure $19 \&$ Figure 20 show the calculated HGLs in different timelines for both the CAVB and PAVB respectively; both the timeline associated with each HGL and the water column velocity in each timeline are labeled at the end of and on the HGL lines respectively. In both cases, the numerical results imply that the whole body of the water column moves with almost the same velocity (marked on the HGLs) during filling.

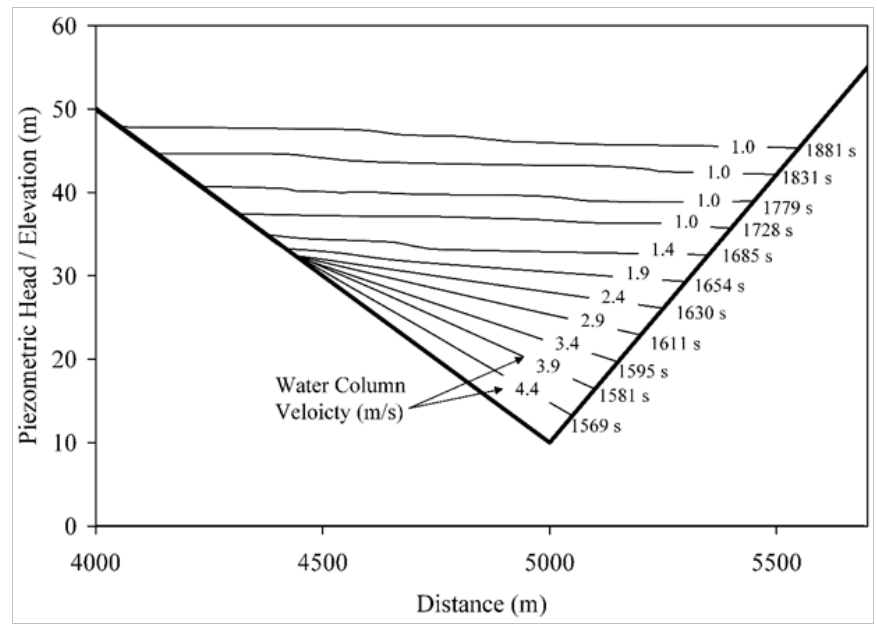

Figure 19 Time history of HGLs in ' $\mathrm{V}$ ' shape pipe profile under the performance of CAVB.

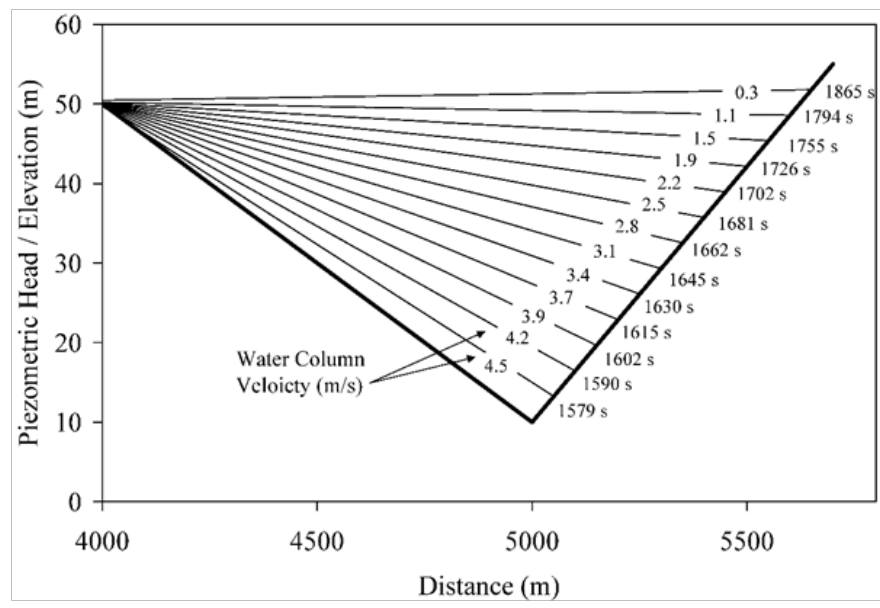

Figure 20 Time history of HGLs in ' $\mathrm{V}$ ' shape pipe profile under the performance of PAVB.

Figure $19 \&$ Figure 20 show that in both cases the water columns reach the end of the descending pipe leg with almost the same velocity of $4.5 \mathrm{~m} / \mathrm{s}$ because the water columns both accelerate under the same pipe slope condition. Nevertheless the HGLs in the CAVB case originate from the high point because the air pocket is assumed to be remain stationary at this point while in the PAVB case the HGLs pivot on a point at which a hydraulic jump changes the flow from open channel to pressurized flow in the descending leg of the ' $\mathrm{V}$ '-shaped profile. Obviously the water column decelerates more quickly in the PAVB than CAVB case because the change in driving head. Figure 18 \& Figure 19 clearly depict that when the water column fronts reach almost the middle of the ascending pipe leg, its velocity drop to $1.4 \mathrm{~m} / \mathrm{s}$ in the PAVB case while it sustains a much higher velocity of $2.8 \mathrm{~m} / \mathrm{s}$ in the CAVB case.
It is worth noting that in the PAVB case, as long as the water column front's elevation in the ascending pipe leg is lower than the hydraulic jump elevation, the HGLs pivot on the same hydraulic jump location. The hydraulic jump location in this period remains fixed because the energy required for the water column to climb in the ascending pipe leg is being supplied as the water column loses its velocity and recovers the associated kinetic energy. However, if the front gains higher elevations, the hydraulic jump will also move upward in order to acquire the required energy to drive the flow. As shown in Figure 20, from this point on the water column velocity remains almost constant at $1 \mathrm{~m} / \mathrm{s}$ because as the water column front elevation further increases the hydraulic jump proportionally moves back to the upstream side in order to compensate for the extra energy required. This makes the ' $\mathrm{V}$ '-shaped profile is being filled under a quasi-steady manner whereby the water column velocity remains almost constant.

In the CAVB case, however, as long as the water column elevation does not exceed the elevation of the knee point, the water column velocity decreases uniformly but when the water column front gains the same elevation of the knee point its velocity suddenly reduces due to the lack of driving head. Figure 19 shows that the water column velocity uniformly changes from 4.5 to 1.1 between the timelines of 1579 and $1794 \mathrm{~s}$ during which the elevation of the water column front remains less than the knee point's elevation, but the velocity suddenly drops to $0.3 \mathrm{~m} / \mathrm{s}$ when the water column front exceed the knee point elevation. From this point on, if the air pocket still exists, the water column velocity can even reach negative value, meaning that a reverse flow occurs. In this case, as shown in Table 1, the water column velocity reaches $-0.2 \mathrm{~m} / \mathrm{s}$ just before the complete removal of the air pocket.

\section{Conclusion}

A new numerical model is employed to explore the effects of AVVs on the hydraulics of rapid pipe filling. The proposed model accounts for water column separation and the performance of AVVs while tracking the water column front. Since the intrusion of large amounts of air during rapid filling may establish two-phase flow in a considerable length of downstream pipe, the CAVB is adjusted to account for the key features of the two-phase flow. It is shown that new approach fixes a flaw with the CAVB; a problem causing under specific condition the numerical model does not converge to correct steady state condition. The proposed model is then employed to investigate the research questions raised in the early part of the paper. These questions can now be provisionally answered: As expected, the numerical exploration reveals that AVVs designed by the conventional criteria can prevent column separation at the air valve location by admitting large air volumes into the pipe system during rapid pipe filling. The admitted air can itself produce water column separation which in turn results in secondary transient pressures.

However, it is confirmed that the shape of the pipeline profile is of great importance in increasing the intensity of the secondary transient pressure. A deep ' $\mathrm{V}$ ' shape profile following the air valve causes a large air pocket to be formed in the system, allowing the adjacent water columns to collide with higher velocity differences. In general, the larger the air pocket that is formed, the higher will be the velocity difference and the more intense secondary transient pressures.

Surprisingly, the reflection of the induced secondary transient pressures at the reservoir and water column front may results in column 
separation in other parts of the system. An air valve's outlet orifice, particularly if it is large, may cause that the water columns at either side of the air valve to collide with higher velocity difference which in turn gives rise to more intense secondary pressures. It is shown that the secondary transient pressures can be circumvented if the air pocket is allowed to be released very slowly; it can be achieved by properly sizing the AVVs' outflow orifice. In cases where the outflow orifice strongly restricts the air flow, it is shown that the proposed air valve boundary condition can successfully account for the air binding and associated reduction in the systems hydraulic capacity.

The numerical results demonstrate that the performance of CAVB causes the model to overestimate the resulting overpressures following the water column rejoining because the downstream water column could unrealistically decelerate to a low velocity causing the water columns on either side of the air pocket to rejoin with a higher velocity difference. Further, it is shown that when using the CAVB, as the descending pipe leg of the ' $\mathrm{V}$ '-shaped profile becomes steeper, stronger water column rejoinders occur. This is attributed to this fact that the steeper pipe slopes allow higher amounts of air to intrude into to the system, thus giving the system more time for the downstream water column to decelerate prior to column rejoinder. However, in the PAVB case, beyond a particular air pocket size, the downstream water column velocity remains almost insensitive to the size of the air pocket, causing that the water column rejoining produces almost the same strength and overpressure. Interestingly, a slight improvement of CAVB permits the model to more realistically capture the expected physics during pipe filling. The implication is that 1-D models still have untapped potential to better replicate the hydraulics of rapid pipe filling.

\section{Notation}

$a=$ Elastic wave velocity;

$A=$ Pipe cross sectional area;

$B_{2}, B_{4}, B_{\nu}, B_{B}=$ Dummy variables;

$C_{1}, C_{2}, C_{3}, C_{4}=$ Positive and negative characteristic line equations' parameters;

$D=$ Pipe Diameter;

$Z_{\text {end }}=$ The pipe elevation at the downstream side of the last pipe;

$f=$ Darcy-Weisbach friction factor;

$F_{f}=$ Friction force;

$F_{g}=$ Gravity force;

$F_{P}=$ Pressure Force;

$F V=$ Generic variable;

$g=$ Gravitational acceleration;

$H=$ Piezometric Head;

$H_{P O d}=$ Piezometric head downstream side of cavity at point $P 0$;

$H_{P O u}=$ Piezometric head upstream side of cavity at point $P 0$;

$H_{P I d}=$ Piezometric head downstream side of cavity at point $P 1$;

$H_{P l u}=$ Piezometric head upstream side of cavity at point $P 1$;

$H_{P 2 d}=$ Piezometric head downstream side of cavity at point $P 2$;
$H_{P 2 u}=$ Piezometric head upstream side of cavity at point $P 2$;

$H_{\text {res }}=$ Reservoir water height;

$H_{V}=$ Gage vapour pressure;

$J=$ Pipe index;

$K_{S}=$ Head loss coefficient accounting for the friction loss in the stagnant water column;

$K_{V}=$ Valve head loss coefficient;

$L=$ Pipe length;

$L_{f}=$ Water column length in the front cell in the previous time line;

$L_{S}=$ initially stagnant water column length;

$m=$ Liquid mass;

$\dot{m}_{i n}=$ The mass rate entering the front cell;

$\dot{m}_{\text {out }}=$ The mass rate leaving the front cell;

$N=$ Number of division of pipes;

$P_{0}^{*}=$ Reference pressure;

$Q_{P O u}=$ Discharge upstream side of cavity at point $P O$;

$Q_{P 0 d}=$ Discharge downstream side of cavity at point $P 0$;

$Q_{P I u}=$ Discharge upstream side of cavity at point $P 1$;

$Q_{P l d}=$ Discharge downstream side of cavity at point $P 1$;

$Q_{P 2 u}=$ Discharge upstream side of cavity at point $P 2$;

$Q_{P 2 d}=$ Discharge downstream side of cavity at point $P 2$;

$S_{0}=$ Pipeline slope;

$S=$ Energy slope;

$t=$ Time;

$V=$ Liquid velocity;

$V_{m}=$ Liquid-water mixture velocity;

$x=$ Distance;

$Z_{P O d}=$ Pipe elevation downstream side of the cavity at point $P 0$;

$Z_{P I d}=$ Pipe elevation downstream side of the cavity at point $P 1$;

$Z_{P 2 d}=$ Pipe elevation downstream side of the cavity at point $P 2$;

$\alpha_{v}=$ Vapour void fraction ;

$\alpha_{0}=$ Initial void fraction;

$\theta=$ Pipe angel respect to the horizontal;

$\psi=$ Time weighting factor;

$\delta x=$ Water column advancement;

$\Delta x=$ Reach length;

$\Delta t=$ Time step;

$\forall_{g}=$ Cavity volume;

$\forall_{R}=$ Computational cell volume;

$\rho=$ Water density; 


\section{Appendix:}

Subsonic air flow in

$$
\dot{m}=C_{i n} A_{i n} \sqrt{7 P_{0} \rho_{0}\left[\left(\frac{P_{\text {air }}}{P_{\text {atm }}}\right)^{1.4286}-\left(\frac{P_{\text {air }}}{P_{\text {atm }}}\right)^{1.714}\right]} \quad P_{\text {atm }}>P_{\text {air }}>0.53 P_{\text {atm }}
$$

Critical air flow in

$$
\dot{m}=C_{i n} A_{i n} \frac{0.686}{\sqrt{R T_{0}}} P_{a t m} \quad P<0.53 P_{a t m}
$$

Subsonic air flow out

$$
\dot{m}=-C_{\text {out }} A_{\text {out }} P_{\text {air }} \sqrt{\frac{7}{R T}\left[\left(\frac{P_{\text {atm }}}{P_{\text {air }}}\right)^{1.4286}-\left(\frac{P_{\text {atm }}}{P_{\text {air }}}\right)^{1.714}\right]} \quad \frac{P_{\text {atm }}}{0.53}>P_{\text {air }}>P_{\text {atm }}
$$

Critical air flow out

$$
\dot{m}=-C_{\text {out }} A_{\text {out }} \frac{0.686}{\sqrt{R T}} P_{\text {air }} \quad P_{\text {air }}>\frac{P_{\text {atm }}}{0.53}
$$

where $P_{\text {atm }}=$ atmospheric absolute pressure, $P_{\text {air }}=$ air cavity absolute pressure, $T_{0}=$ absolute temperature outside of the pipe, $T=$ absolute temperature inside of the pipe, $\rho_{0}=$ mass density of atmospheric air, $C_{\text {in }}=$ valve discharge coefficient for inflow, $C_{\text {out }}=$ valve discharge coefficient for outflow, $A_{\text {in }}=$ air inlet opening area of the valve, and $A_{\text {out }}=$ air outlet opening area of the valve.

\section{Acknowledgments}

None.

\section{Conflicts of interest}

The author declares there is no conflicts of interest.

\section{References}

1. Pozos O, Giesecke J, Marx W, et al. Experimental investigation of air pockets in pumping pipeline systems. Journal of Hydraulic Research 2010;48(2):269-273

2. Pozos O, Giesecke J, Marx W, et al. Air entrapped in gravity pipeline systems. Journal of Hydraulic Research. 2010;48(3):338-347.

3. Falvey HT. Air-Water Flow in Hydraulic Structures. 1980.

4. Lingireddy S, Wood DJ, Zloczower N. Pressure Surges in Pipeline Systems Resulting from Air Releases. Journal of American Water Work Association. 2004;96(7):88-94.

5. Lee TS. Air Influence on Hydraulic Transients on Fluid System with Air Valves. Journal of Fluid Engineering. 1999;121(3):647-650.

6. Lee TS, Leow LC. Numerical study on the effects of air valve characteristics on pressure surges during pump trip in pumping systems with Air entrainment. International Journal for Numerical Methods in Fluids. 1999;29(6):645-655.

7. Chaiko MA, Brinckman KW. Models for analysis of water hammer in piping with entrapped air. Journal of Fluid Engineering. 2002;124(1):194-204.

8. Carlos M, Arregui FJ, Cabrera E, et al. Understanding air release through air valves. Journal of Hydraulic Engineering. 2011;137(4):461-469.

9. Radulj D. The role of air valves in water distribution systems. 2010.
10. Izquierdo J, Fuertes V, Cabrera E, et al. Pipeline start-up with entrapped air. Journal of Hydraulic Research. 1999;37(5):579-590.

11. Malekpour A, BW Karney. Rapid filling analysis of pipelines with undulating profiles by the method of characteristic. ISRN Applied Mathematics. 2011.

12. Zhou F, Hicks FE, Steffler PM. Transient flow in a rapidly filling horizontal pipe containing trapped air. Journal of Hydraulic Engineering. 2002;128(6):625-634.

13. Martin C. Experimental investigation of column separation with rapid closure of downstream valve. 1983.

14. Cabrera E, Abreu J, Perez R, et al. Influence of liquid length variation in hydraulic transients. Journal of Hydraulic Engineering. 1992;18(12):1639-1650.

15. Liu D, Zhou L, Karney B, et al. Rigid-plug elastic-water model for transient pipe flow with entrapped air pocket. Journal of Hydraulic Research. 2011;49(6):799-803.

16. Bergant A, Kruisbrink A, Arregui F.Dynamic behaviour of air valves in a large-scale pipeline apparatus. Strojniški vestnik-Journal of Mechanical Engineering. 2012;58(4):225-237.

17. SimpsonA, Wylie E. Large water-hammer pressures for column separation in pipelines. Journal of Hydraulic Engineering. 1991;117(10):1310 1316.

18. Bergant A, Simpson AR. Pipeline column separation flow regimes Journal of Hydraulic Engineering. 1999;125(8):835-848.

19. Chaiko MA. A finite volume approach for simulation of liquid-column separation in pipelines. Journal of fluids engineering. 2006;128(6):1324 1335 .

20. Adamkowski A, Lewandowski M. Investigation of hydraulic transients in a pipeline with column separation. Journal of Hydraulic Engineering. 2012;138(11):935-944.

21. List E, Burnam J, Solbrig R, et al. Vapor cavity formation and collapse: field evidence for major pipeline damage. New York, N.Y.: American Society of Mechanical Engineers. 2000;3:235-242.

22. Liou CP, Hunt W A. Filling of pipelines with undulating elevation profiles. Journal of Hydraulic Engineering. 1996;122(10):534-539.

23. Malekpour A, Karney BW. Rapid filling in pipe systems with column separation. 2012

24. Malekpour A, Karney BW. Profile-induced column separation and rejoining during rapid pipeline filling. Journal of Hydraulic Engineering. 2014;140(11).

25. Malekpour A, Karney BW. Column separation and rejoinder during rapid pipeline filling induced by a partial flow blockage. Journal of Hydraulic Research. 2014;52(5):693-704.

26. Wylie EB, Streeter VL. Fluid transients in systems. 1993.

27. Kerger F, Archambeau P, Dewals BJ, et al. Three-phase bi-layer model for simulating mixed flows. Journal of Hydraulic Research. 2012;50(3):312-319.

28. Pothof IWM, Clemens FHLR. Experimental study of air-water flow in downward sloping pipes. International journal of multiphase flow. 2011;37(3):278-292.

29. Hou Q. Simulating unsteady conduit flows with smoothed particle hydrodynamics. The Netherlands: Eindhoven University of Technology. 2012.

30. Rossman LA. Storm water management model user's manual, version 5.0. 2015 .

31. Awwa. Air-release, air/vacuum, and combination air valves. 2001. 